\title{
Insect GPCRs and TRP Channels: Putative Targets for Insect Repellents
}

\author{
Sang Hoon Kim* \\ Department of Biological Chemistry, Johns Hopkins University School of Medicine, Baltimore, Maryland, U.S.
}

Subject areas; Biomathematics/Mathematical Biology and Medicine, General Author contribution; S.H.K. wrote the
manuscript.

${ }^{*}$ Correspondence and requests for materials should be addressed to S.H.K. (skim219@jhmi. edu).

Editor; Hong Gil Nam, Daegu Gyeongbuk Institute of Science \&t Technology, Korea

Received July 18, 2013;

Accepted July 31, 2013

Published July 31, 2013

Citation; Kim, S.H. Insect GPCRs and TRP Channels: Putative Targets for Insect Repellents. IBC 2013, 5:6, 1-7.

doi: 10.4051/ibc.2013.5.3.0006

Funding; Samsung Scholarship Foundation

Competing interest; All authors declare no financial or personal conflict that could inappropriately bias their experiments or writing. (c) Kim, SH. This is an Open Access article distributed under the terms of the Creative Commons Attribution Non-Commercial License (http://creativecommons.org/licenses/by-nc/3.0) which permits unrestricted non-commercial use, distribution, and reproduction in any medium, provided the original work is properly cited.

\section{SYNOPSIS}

Many insects such as mosquitoes cause life-threatening diseases such as malaria, yellow fever and West Nile virus. Malaria alone infects 500 million people annually and causes 1-3 million death per year. Volatile insect repellents, which are detected through the sense of smell, have long been used to protect humans against insect pests. Antifeedants are non-volatile aversive compounds that are detected through the sense of taste and prevent insects from feeding on plants. The molecular targets and signaling pathways required for sensing insect repellents and antifeedants are poorly understood.

Transient Receptor Potential (TRP) Ca2+-permeable cation channels exist in organisms ranging from $C$. elegans to $D$. melanogaster and Homo sapiens. Drosophila has 13 family members, which mainly function in sensory physiology such as vision, thermotaxis and chemotaxis. G protein-coupled receptors (GPCRs) initiate olfactory signaling cascades in mammals and in nematodes $C$. elegans. However, the mechanisms of $\mathrm{G}$ protein signaling cascades in insect chemosensation are controversial.

In this review, I will discuss the putative roles of G protein-coupled receptors (GPCRs) and Transient Receptor Potential (TRP) channels as targets for insect repellents.

\begin{tabular}{lc}
\hline & Compounds \\
\hline Insect Repellents & Synthetic : DEET \\
Natural : Citronellal, Geraniol \\
Olfactory attractants & $\mathrm{CO}_{2}, 1$-octen-3-ol \\
Pheromones & cis-vaccenyl acetate (cVA) \\
Antifeedants & Bitter compounds \\
\hline
\end{tabular}

Key Words: GPCRs; TRP channels; olfaction; taste; insect repellents 


\section{OVERVIEW}

Taste and smell are critical sensory modalities for survival since insects need to discriminate safe from noxious foods and toxic odors. Most insects are deleterious for plants. Thus, plants produce compounds to protect them from insect pests. Some chemicals are volatile repellents, which deter insects from landing on the plant. Other chemicals are non-volatile compounds, referred to as antifeedants, which inhibit the propensity for insects to feed on plants. Insect pests can detect repellents through the sense of smell and antifeedants through sense of taste.

Studying insect repellents and antifeedants is very important since they can reduce insect borne disease (repellents) or protect crops from damage (antifeedants). Insects are the vectors for many infectious diseases such as malaria, yellow fever and West Nile virus. For example, Anopheles gambiae is the vector for malaria and Aedes aegypti is the vector for Dengue fever and yellow fever. Malaria alone infects an estimated 500 million people annually and causes 1 million deaths per year ${ }^{1}$. Moreover, the control of insect pests is important for decreasing crop destruction. Insect pests contribute to loss of fourteen percent of total crops. About $\$ 200$ billion per year in the United States and $\$ 2$ trillion worldwide are lost to insect destruction ${ }^{2}$. Nevertheless, the molecular targets and signaling pathways required for sensing insect repellents and antifeedants are poorly understood. In this review, I will discuss the putative roles of $\mathrm{G}$ proteincoupled receptors (GPCRs) and Transient Receptor Potential (TRP) channels as targets for insect repellents.

\section{DIVERSE STRATEGIES OF CHEMOSENSORY-BASED INSECT CONTROL}

Diverse chemosensory-based strategies have been used in attempts to control insect pests ${ }^{3}$. Olfactory attractants, such as CO2 or 1-octanol are used to lure insects to a trap. Pheromones have also been used effectively as trapping agents or to disrupt mating. Volatile insect repellents, which are detected through the sense of smell, have long been used to protect humans against insect pests. The most commonly-used synthetic repellent is DEET. However, there are some limitations. These include low potency, short range, and ineffectiveness against bees and certain mosquitoes ${ }^{4}$. Also, it cannot be applied to some synthetic fabrics and leather.

Thus, the use of plant-derived essential oils is widely considered as alternatives for synthetic insect repellents such as DEET. Citronellal, geraniol and camphor are among the most popular plant derived insect repellents ${ }^{5}$. Citronellal is commonly used in lotions, sprays and candles to repel mosquitoes and reduce the incidence of insect bites. Geraniol also shows repellency against a wide range of biting insects, including mosquitoes, flies,
Table 1. Chemosensory based insect control

\begin{tabular}{lc}
\hline & Compounds \\
\hline Insect Repellents & Synthetic : DEET \\
& Natural : Citronellal, Geraniol \\
Olfactory attractants & $\mathrm{CO}_{2}, 1$-octen-3-ol \\
Pheromones & cis-vaccenyl acetate $(\mathrm{cVA})$ \\
Antifeedants & Bitter compounds \\
\hline
\end{tabular}

fire ants and ticks ${ }^{6}$. Their repellent efficiencies against mosquitoes have been verified.

Antifeedants are non-volatile aversive compounds that are detected through the sense of taste and prevent insects from feeding on plants. However, they do not necessarily repel insects. An antifeedant may cause an insect to starve to death, since it inhibits feeding, but it may not cause the insect to move away from the source. Many plant-derived natural compounds such as aristolochic acid can be used as antifeedants ${ }^{3}$. Most of the chemosensory-based control strategies described here were not based on the molecular understanding of insect chemosensation. Thus, further understanding of insect olfaction and taste would contribute to identify molecular targets for insect pest control.

\section{DROSOPHILA OLFACTORY SYSTEM}

Drosophila serves as an excellent model organism to investigate the mechanisms underlying olfaction. The antenna and maxillary palp are the main sensory organs for sensing volatile compounds in Drosophila ${ }^{7}$. Each antenna and maxillary palp is covered with hair-like sensilla. And each sensillum houses around 1-4 olfactory receptor neurons (ORNs) that are surrounded by support cells. The antenna has three distinct morphological and functional types of sensilla: club-shaped basiconic sensilla, long and pointed trichoid sensilla and short coeloconic sensilla ${ }^{8}$. The different sensilla are distributed in a highly stereotyped pattern. Large basiconic sensilla are clustered at the medial-proximal side of the antenna, while tricoid sensilla are clustered at the lateral-distal edge. Small basiconic and coeloconic sensilla are distributed in the middle region on the antenna. The maxillary palp has a simpler structure than the antenna and contains only one class of basiconic sensilla. The antenna has about 410 olfactory sensilla, whereas about 60 olfactory sensilla cover the maxillary palp ${ }^{8}$. In total, there are between 1,100-1,250 ORNs in each antenna and 120 ORNs in the maxillary palp ${ }^{9}$. All ORNs express a unique combination of olfactory receptors (ORs) and project axon into a single olfactory glomerulus in the antennal lobe (AL), which is the functional homolog of mammalian olfactory bulb.

Drosophila olfactory receptors (ORs) were identified using computational and molecular approaches ${ }^{10,11}$. There are 62 ORs 
transcribed from 60 OR genes. ORN expresses up to three single ligand-binding Ors, along with an olfactory co-receptor, Orco (previously known as Or83b). Orco is expressed in most ORNs and is required for trafficking and functioning of ORs in Drosophila ${ }^{12}$. Odorants pass through the pores in the sensillum, interact with ORs on the membranes of sensory dendrites from ORNs and induce action potential in these neurons.

Single sensillum recordings, which measure the frequencies of action potentals in ORNs, are used to define the olfactory profiles of basiconic and coeloconic sensilla on the antenna and maxillary palp ${ }^{13-15}$. Specific ORs are assigned to specific sensilla types, which have specialized ligands. Basiconic sensilla are specialized to detect food odors, whereas tricoid sensilla appear to detect pheromones ${ }^{16,17}$. The coeloconic sensilla are specialized for detecting water vapor, ammonia and putrescine ${ }^{18}$. In addition to ORs, ionotropic glutamate receptors (IRs) sense odorants ${ }^{19}$.

\section{DROSOPHILA GUSTATORY SYSTEM}

Unlike mammalian taste, which is mediated through taste buds on the tongue, the taste organs in fruit flies are distributed over multiple body parts. Flies detect tastants using taste bristles (sensilla) distributed at the tip of the proboscis (labella), legs and wings ${ }^{20}$. Each labellum on the proboscis has 31 taste bristles, each containing 2-4 gustatory receptor neurons (GRNs), one mechanosensory neuron and three accessory cells. GRNs in the proboscis have a single dendrite that extends to the tip of the sensilla and project an axon into the subesophageal ganglion (SOG) region of the brain ${ }^{21}$.

The three types of taste sensilla on the labellum are categorized by length (long; l-type; intermediate, i-type; and short, stype $)^{22}$. The four kinds of GRNs in s-type and l-type sensilla show responses to four taste modalities: sugar ( $\mathrm{S}$ cell), water (W cell), low concentrations of salt (L1) and high salt concentration and bitter compounds (L2). Bitter compounds also inhibit activity of the $\mathrm{S}$ cells and W cells. The i-type sensilla have only two GRNs. The first GRN responds to sugars and low salt, while the second GRN responds to bitter compounds and high salt ${ }^{23}$. Each sensilla has relatively different responses to sugar and bitter compounds. In general, the l-type sensilla produce stronger responses to sugars, while the i- and s-type sensilla respond to bitter compounds strongly. Flies also detect tastants with gustatory sensilla in their legs and wing margin $\mathrm{s}^{24}$. Each leg has 30 to 50 taste senslla and each sensillum contains around two to four GRNs. The wing margin houses 40 taste sensilla, each containing four GRNs.

Drosophila GRs were identified through analysis of genomic DNA sequences ${ }^{25}$. There are 68 GRs in Drosophila ${ }^{26}$. Gr5a and Gr66a are expressed in a very large number of non-overlapping
GRNs. GR66a is broadly expressed in bitter-responsive GRNs, whereas Gr5a broadly marks sugar-responsive GRNs. Genetic ablation experiments for Gr5a or Gr66a expressing neurons suggest that these GRNs are required for sensing bitter compounds and sugars, respectively ${ }^{21,27-29}$.

\section{TRANSIENT RECEPTOR POTENTIAL (TRP) CHANNELS IN CHEMOSENSATION}

TRP channels are non-selective cation channels conserved from worms to flies and humans ${ }^{30}$. The first TRP channel member, TRP, was identified by characterizing a Drosophila mutant with a defect in visual transduction ${ }^{31,32}$. Drosophila has 13 TRP channel family members and these channels function in various sensory modalities such as vision, gravitaxis and thermotaxis. For example, TRPA subfamily members, TRPAl, Pain and Pyrexia participate in the detection of hot temperatures ${ }^{33-35}$. At least five TRP channels are required for gravity sensation or sound sensation ${ }^{36-38}$.

Several TRP channel family members in C. elegans and mammals participate in chemosensation. In C. elegans, the TRPV family member, OSM-9 functions in sensing odorants ${ }^{39}$. In addition, mutant worms lacking TRPC channel are impaired in their response to nicotine ${ }^{40}$. In mammalian organisms, several thermo-sensitive TRP channels also function in the detection of noxious or pungent chemicals. For example, TRPAl is chemically activated by pungent compounds such as wasabi, garlic (allicin), mustard oils (isothiocyanates), and cinnamon oil (cinnamaldehyde) ${ }^{41}$.

Drosophila TRP channels also function in chemosensation. One of the most commonly used plant-derived insect repellents is citronellal. Citronellal is used commonly in lotions, sprays, and candles to repel mosquitoes, fleas, and ticks. A recent study indicates that Drosophila TRPAl is required for avoiding the volatile insect repellent citronellal. The response to citronellal relied on a G protein (Gq)/PLC signaling cascade rather than direct detection of citronellal by TRPA1 ${ }^{42}$. In contrast to fly TRPAl, Anopheles gambiae TRPAl was directly and potently activated by citronellal. In addition to olfactory function, Drosophila TRPAl was required in gustatory receptor neurons for the behavioral and electrophysiological responses to the antifeedant, aristolochic acid ${ }^{43}$. TRPAl was not activated directly by aristolochic acid, but was coupled to a PLC signaling cascade. Drosophila TRPA1 is also expressed in GRNs and can be directly activated by AITC, the pungent component in wasabi ${ }^{44}$. Another TRPA family member, Painless is also expressed in GRNs and is required for avoidance to $\mathrm{AITC}^{45}$. However, it is not known whether Painless senses wasabi in GRNs. It is also unclear whether Painless senses wasabi directly or through a signaling pathway. 


\section{GPCRS SIGNALING IN OLFACTION}

G protein-coupled receptors (GPCRs) constitute a large superfamily of seven transmembrane proteins that sense molecules outside the cell and activate signal transduction pathways ${ }^{46}$. GPCRs interact with a family of heterotrimeric GTP binding proteins, referred to as $\mathrm{G}$ proteins (Gs, Gi/o, and Gq). Ligandinduced activation of GPCRs induces a conformational change of the receptor and triggers $\mathrm{G}$ proteins that in turn regulate the activity of other effector molecules. In general, Gs subunits regulate the activation of adenylyl cyclase, resulting in an increased synthesis of cAMP. The Gi/o class of G proteins activates phosphodiesterases, which leads to the inhibition of stimulated cAMP. Finally, Gq subunits couple to phospholipaseC $\beta$ (PLC $\beta$ ), thereby producing diacylglycerol (DAG) and inositol triphosphate (IP). DAG activates protein kinase $\mathrm{C}$ whereas IP mobilizes intracellular Ca2+. Drosophila encodes about 117 canonical GPCRs, whereas more than 1,000 GPCRs are encoded in vertebrates and C. elegans ${ }^{47}$.

\section{GPCRS SIGNALING IN OLFACTION}

There is broad evidence that GPCRs initiate olfactory signaling cascade in mammals and the nematode. Mammalian ORs are GPCRs, which bind to odorants in the ciliary membrane. This activates a $\mathrm{G}$ protein that, which in turn, stimulates adenylate cyclase (AC). cAMP directly gates cyclic nucleotide-gated (CNG) ion channels causing an odorant-induced inward current carried by $\mathrm{Na}+$ and $\mathrm{Ca} 2+$ ions $^{48}$.

Currently, the mechanisms underlying insect olfactory signaling is controversial. Our understanding of the molecular components required for sensing odorants in insects is limited primarily to Ors and IRs. Although Drosophila ORs were widely assumed to be GPCRs, several studies suggest that insect ORs have a topology opposite to conventional GPCRs. Moreover, fly ORs have no amino acid homology to mammalian and C. elegans $\mathrm{ORs}^{49-52}$. In addition, insect ORs do not have conventional binding sites for $\mathrm{G}$ proteins. One report concludes that ORs are strictly ligand-gated channels ${ }^{53}$. In contrast, another study suggests that ORs are both ligand gated channels and GPCRs ${ }^{54}$.

In one study, expression of ORs in heterologous systems ${ }^{55} \mathrm{in}$ dicates that ORs and Orco form a non-selective cation channel and are activated by odorants to produce fast ionotropic response, which does not require $G$ proteins. However, a second study indicates that $\mathrm{G}$ protein signaling cascades mediate the slower metabotropic pathway, which leads to the production of second messengers, and activation of Orco. According to this model, the ionotropic pathway functions at higher odorants concentrations, whereas the metabotropic pathway amplifies signal at low odorants concentrations in a $\mathrm{G}$ protein-dependent manner. These data suggest that canonical GPCRs may initiate $G$ proteins signaling cascades in ORNs for odorants sensation.

Despite the controversy as to whether or not ORs can capable of functioning as GPCRs, $\mathrm{G}$ proteins are expressed in $\mathrm{ORNs}^{56}$. Gs and $\mathrm{Gq}$ are enriched in the dendrites of ORNs, suggesting that $\mathrm{G}$ protein might function in olfactory transduction ${ }^{57-61}$. A fly mutant disrupting the $\mathrm{dGq}$ gene encoding the $\mathrm{Gq} \alpha$ subunit shows reduced responses to odor stimulation ${ }^{58}$. The odor-induced response was further attenuated by mutations in plc21C, a gene encoding a PLC $\beta$.

\section{G PROTEINS SIGNALING CASCADE IN TASTE SENSATION}

Mammalian sweet, bitter and umami taste all depend on PLC signaling and the TRPM5 channel ${ }^{62,63}$. The specificity for different bitter and sweet tastants is mediated by GPCRs. Two classes of taste GPCRs have been identified: T1Rs and T2Rs64. T1R family members consist of three receptors: T1R1, T1R2 and T1R3 and function as heterodimers. T1R1 + T1R3 and T1R2 + T1R3 mediate umami taste and the sweet taste, respectively ${ }^{65,66}$. In addition, T2Rs, which consist of about 30 members in mammals, mediate bitter taste ${ }^{67}$.

It is not clear whether insects use single signaling mechanism to sense all tastants in GRNs. It has been proposed that Manduca sexta use multiple transduction pathways that functions in response to bitter compounds, such as aristolochic acid and caffein $\mathrm{e}^{68,69}$. The molecules whose roles in Drosophila taste are best understood are GRs. These proteins have no homology with mammalian GPCRs. A recent report suggests that Bombyx mori GR-9 (BmGR-9), and its Drosophila homolog, Gr43a, constitute a ligand-gated ion channel ${ }^{70}$. It is still controversial whether the Drosophila GRs are cation channels. As is the case for insect olfaction, the Drosophila gustatory system appears to employ $\mathrm{G}$ protein-mediated signaling pathways. Mutations disrupting Gas, Gaq, G $\gamma 1$, or phospholipid signaling caused partial reductions in the trehalose response $\mathrm{e}^{4,71}$. In addition, Goo functions in the detection of sucrose, glucose, and fructose in Drosophila $^{72}$. However, there was no report suggesting that PLC was involved in an insect taste signaling cascade. The fact that mammalian taste is mediated by a single PLC/TRPM5 transduction pathway raises the possibility that insects might use PLC and TRP channel signaling for taste sensation.

\section{POTENTIAL MOLECULAR TARGETS FOR INSECT REPELLENTS}

The identification of receptors for insect repellents would provide new opportunities for insect pest control. Specifically, these receptors could be used to perform high-throughput chemical 
screens for activators of the receptors, which might serve as new, highly potent insect repellents. However, the direct molecular targets for insect repellents are poorly understood. A recent study indicates that olfactory receptors are targets for the most commonly used repellent, DEET (N,N-diethyl-m-toluamide). However, the mode of action of DEET is still controversial. It has been proposed that DEET does not act directly as a volatile repellent but inhibits olfactory responses to attractive compounds $\mathrm{s}^{73,74}$. Another study suggests that ORNs in the mosquito, Culex quinquefasciatus, respond directly to $\mathrm{DEET}^{75}$.

TRP channels and GPCRs represent additional candidate targets for insect repellents. Recent study suggests that mosquito TRPAl is directly and potently activated by insect repellent citronellal ${ }^{42}$. It raises the exciting possibility that high-throughput screens for novel activators of mosquito TRPA channel might lead to the discovery of improved repellents to control insectborne disease. In addition, $\mathrm{G}$ protein signaling cascades participate in some aspects of chemosensation in ORNs and GRNs ${ }^{57-}$ ${ }_{61,71,76}$. Thus, GPCRs might function as putative targets for insect repellents.

\section{REFERENCES}

1. Snow, R. W., Guerra, C. A., Noor, A. M., Myint, H. Y., and Hay, S. I. (2005). The global distribution of clinical episodes of Plasmodium falciparum malaria. Nature 434, 214-217.

2. Pimentel, D. (2009) Pesticides and Pest Control. In: R. Peshin and A. Dhawan, editors. Integrated Pest Management: Innovation-Development Process: Springer Netherlands. pp. 83-87.

3. van der Goes van Naters, W., and Carlson, J. R. (2006). Insects as chemosensors of humans and crops. Nature 444, 302-307.

4. Katz, T. M., Miller, J. H., and Hebert, A. A. (2008). Insect repellents: historical perspectives and new developments. Journal of the American Academy of Dermatology 58, 865-871.

5. Isman, M. B. (2006). Botanical insecticides, deterrents, and repellents in modern agriculture and an increasingly regulated world. Annual Review of Entomology 51, 45-66.

6. Omolo, M. O., Okinyo, D., Ndiege, I. O., Lwande, W., and Hassanali, A. (2004). Repellency of essential oils of some Kenyan plants against Anopheles gambiae. Phytochemistry 65, 2797-2802.

7. Vosshall, L. B., and Stocker, R. F. (2007). Molecular architecture of smell and taste in Drosophila. Annual Review of Neuroscience 30, 505-533.

8. Laissue, P. P., and Vosshall, L. B. (2008). The olfactory sensory map in Drosophila. Advances in Experimental Medicine and Biology 628, 102114.

9. Stocker, R. F. (2001). Drosophila as a focus in olfactory research: mapping of olfactory sensilla by fine structure, odor specificity, odorant receptor expression, and central connectivity. Microscopy Research and Technique 55, 284-296.

10. Clyne, P. J., Warr, C. G., Freeman, M. R., Lessing, D., Kim, J., and Carlson, J. R. (1999). A novel family of divergent seven-transmembrane proteins: candidate odorant receptors in Drosophila. Neuron 22, 327-338.
11. Vosshall, L. B., Amrein, H., Morozov, P. S., Rzhetsky, A., and Axel, R. (1999). A spatial map of olfactory receptor expression in the Drosophila antenna. Cell 96, 725-736.

12. Larsson, M. C., Domingos, A. I., Jones, W. D., Chiappe, M. E., Amrein, H., and Vosshall, L. B. (2004). Or83b encodes a broadly expressed odorant receptor essential for Drosophila olfaction. Neuron 43, 703-714.

13. Goldman, A. L., Van der Goes van Naters, W., Lessing, D., Warr, C. G., and Carlson, J. R. (2005). Coexpression of two functional odor receptors in one neuron. Neuron 45, 661-666.

14. Hallem, E. A., Dahanukar, A., and Carlson, J. R. (2006). Insect odor and taste receptors. Annual Review of Entomology 51, 113-135.

15. Kreher, S. A., Kwon, J. Y., and Carlson, J. R. (2005). The molecular basis of odor coding in the Drosophila larva. Neuron 46, 445-456.

16. Clyne, P., Grant, A., O'Connell, R., and Carlson, J. R. (1997). Odorant response of individual sensilla on the Drosophila antenna. Invertebrate Neuroscience: IN 3, 127-135.

17. Ha, T. S., and Smith, D. P. (2006). A pheromone receptor mediates 11-cisvaccenyl acetate-induced responses in Drosophila. The Journal of neuroscience : the Official Journal of the Society for Neuroscience 26, 87278733.

18. Yao, C. A., Ignell, R., and Carlson, J. R. (2005). Chemosensory coding by neurons in the coeloconic sensilla of the Drosophila antenna. The Journal of Neuroscience : the Official Journal of the Society for Neuroscience 25, 8359-8367.

19. Benton, R., Vannice, K. S., Gomez-Diaz, C., and Vosshall, L. B. (2009). Variant ionotropic glutamate receptors as chemosensory receptors in Drosophila. Cell 136, 149-162.

20. Montell, C. (2009). A taste of the Drosophila gustatory receptors. Current Opinion in Neurobiology 19, 345-353.

21. Thorne, N., Chromey, C., Bray, S., and Amrein, H. (2004). Taste perception and coding in Drosophila. Current Biology: CB 14, 1065-1079.

22. Hiroi, M., Marion-Poll, F., and Tanimura, T. (2002). Differentiated response to sugars among labellar chemosensilla in Drosophila. Zoological Science 19, 1009-1018.

23. Hiroi, M., Meunier, N., Marion-Poll, F., and Tanimura, T. (2004). Two antagonistic gustatory receptor neurons responding to sweet-salty and bitter taste in Drosophila. Journal of Neurobiology 61, 333-342.

24. Stocker, R. F. (1994). The organization of the chemosensory system in Drosophila melanogaster: a review. Cell and Tissue Research 275, 3-26.

25. Clyne, P. J., Warr, C. G., and Carlson, J. R. (2000). Candidate taste receptors in Drosophila. Science 287, 1830-1834.

26. Robertson, H. M., Warr, C. G., and Carlson, J. R. (2003). Molecular evolution of the insect chemoreceptor gene superfamily in Drosophila melanogaster. Proceedings of the National Academy of Sciences of the United States of America 100 Suppl 2, 14537-14542.

27. Chyb, S., Dahanukar, A., Wickens, A., and Carlson, J. R. (2003). Drosophila Gr5a encodes a taste receptor tuned to trehalose. Proceedings of the National Academy of Sciences of the United States of America 100 Suppl 2, 14526-14530.

28. Ueno, K., Ohta, M., Morita, H., Mikuni, Y., Nakajima, S., Yamamoto, K., and Isono, K. (2001). Trehalose sensitivity in Drosophila correlates with mutations in and expression of the gustatory receptor gene Gr5a. Current Biology: CB 11, 1451-1455.

29. Wang, Z., Singhvi, A., Kong, P., and Scott, K. (2004). Taste representa- 
tions in the Drosophila brain. Cell 117, 981-991.

30. Venkatachalam, K., and Montell, C. (2007). TRP channels. Annual Review of Biochemistry 76, 387-417.

31. Montell, C., Jones, K., Hafen, E., and Rubin, G. (1985). Rescue of the Drosophila phototransduction mutation trp by germline transformation. Science 230, 1040-1043.

32. Montell, C., and Rubin, G. M. (1989). Molecular characterization of the Drosophila trp locus: a putative integral membrane protein required for phototransduction. Neuron 2, 1313-1323.

33. Lee, Y., Lee, Y., Lee, J., Bang, S., Hyun, S., Kang, J., Hong, S. T., Bae, E., Kaang, B. K., and Kim, J. (2005). Pyrexia is a new thermal transient receptor potential channel endowing tolerance to high temperatures in Drosophila melanogaster. Nature Genetics 37, 305-310.

34. Neely, G. G., Keene, A. C., Duchek, P., Chang, E. C., Wang, Q. P., Aksoy, Y. A., Rosenzweig, M., Costigan, M., Woolf, C. J., Garrity, P. A., et al. (2011). TrpA1 regulates thermal nociception in Drosophila. PloS One 6, e24343.

35. Tracey, W. D., Jr., Wilson, R. I., Laurent, G., and Benzer, S. (2003). painless, a Drosophila gene essential for nociception. Cell 113, 261-273.

36. Gong, Z., Son, W., Chung, Y. D., Kim, J., Shin, D. W., McClung, C. A., Lee, Y., Lee, H. W., Chang, D. J., Kaang, B. K., et al. (2004). Two interdependent TRPV channel subunits, inactive and Nanchung, mediate hearing in Drosophila. The Journal of Neuroscience : the Official Journal of the Society for Neuroscience 24, 9059-9066.

37. Kim, J., Chung, Y. D., Park, D. Y., Choi, S., Shin, D. W., Soh, H., Lee, H. W., Son, W., Yim, J., Park, C. S., et al. (2003). A TRPV family ion channel required for hearing in Drosophila. Nature 424, 81-84.

38. Sun, Y., Liu, L., Ben-Shahar, Y., Jacobs, J. S., Eberl, D. F., and Welsh, M. J. (2009). TRPA channels distinguish gravity sensing from hearing in Johnston's organ. Proceedings of the National Academy of Sciences of the United States of America 106, 13606-13611.

39. Kahn-Kirby, A. H., and Bargmann, C. I. (2006). TRP channels in C. elegans. Annual Review of Physiology 68, 719-736.

40. Feng, Z., Li, W., Ward, A., Piggott, B. J., Larkspur, E. R., Sternberg, P. W., and $\mathrm{Xu}, \mathrm{X}$. Z. (2006). A C. elegans model of nicotine-dependent behavior: regulation by TRP-family channels. Cell 127, 621-633.

41. Bandell, M., Story, G. M., Hwang, S. W., Viswanath, V., Eid, S. R., Petrus, M. J., Earley, T. J., and Patapoutian, A. (2004). Noxious cold ion channel TRPA1 is activated by pungent compounds and bradykinin. Neuron 41 , 849-857.

42. Kwon, Y., Kim, S. H., Ronderos, D. S., Lee, Y., Akitake, B., Woodward, O. M., Guggino, W. B., Smith, D. P., and Montell, C. (2010). Drosophila TRPAl channel is required to avoid the naturally occurring insect repellent citronellal. Current Biology : CB 20, 1672-1678.

43. Kim, S. H., Lee, Y., Akitake, B., Woodward, O. M., Guggino, W. B., and Montell, C. (2010). Drosophila TRPA1 channel mediates chemical avoidance in gustatory receptor neurons. Proceedings of the National Academy of Sciences of the United States of America 107, 8440-8445.

44. Kang, K., Pulver, S. R., Panzano, V. C., Chang, E. C., Griffith, L. C., Theobald, D. L., and Garrity, P. A. (2010). Analysis of Drosophila TRPA1 reveals an ancient origin for human chemical nociception. Nature 464, 597-600.

45. Al-Anzi, B., Tracey, W. D., Jr., and Benzer, S. (2006). Response of Drosophila to wasabi is mediated by painless, the fly homolog of mammalian TRPA1/ANKTM1. Current Biology: CB 16, 1034-1040.
46. Meeusen, T., Mertens, I., De Loof, A., and Schoofs, L. (2003). G proteincoupled receptors in invertebrates: a state of the art. International Review of Cytology 230, 189-261.

47. Wettschureck, N., and Offermanns, S. (2005). Mammalian G proteins and their cell type specific functions. Physiological Reviews 85, 1159-1204.

48. Pifferi, S., Boccaccio, A., and Menini, A. (2006). Cyclic nucleotide-gated ion channels in sensory transduction. FEBS Letters 580, 2853-2859.

49. Benton, R., Sachse, S., Michnick, S. W., and Vosshall, L. B. (2006). Atypical membrane topology and heteromeric function of Drosophila odorant receptors in vivo. PLoS Biology 4, e20.

50. Lundin, C., Kall, L., Kreher, S. A., Kapp, K., Sonnhammer, E. L., Carlson, J. R., Heijne, G., and Nilsson, I. (2007). Membrane topology of the Drosophila OR83b odorant receptor. FEBS Letters 581, 5601-5604.

51. Smart, R., Kiely, A., Beale, M., Vargas, E., Carraher, C., Kralicek, A. V., Christie, D. L., Chen, C., Newcomb, R. D., and Warr, C. G. (2008). Drosophila odorant receptors are novel seven transmembrane domain proteins that can signal independently of heterotrimeric G proteins. Insect Biochemistry and Molecular Biology 38, 770-780.

52. Wistrand, M., Kall, L., and Sonnhammer, E. L. (2006). A general model of $\mathrm{G}$ protein-coupled receptor sequences and its application to detect remote homologs. Protein Science : a Publication of the Protein Society 15, 509-521.

53. Sato, K., Pellegrino, M., Nakagawa, T., Nakagawa, T., Vosshall, L. B., and Touhara, K. (2008). Insect olfactory receptors are heteromeric ligandgated ion channels. Nature 452, 1002-1006.

54. Wicher, D., Schafer, R., Bauernfeind, R., Stensmyr, M. C., Heller, R., Heinemann, S. H., and Hansson, B. S. (2008). Drosophila odorant receptors are both ligand-gated and cyclic-nucleotide-activated cation channels. Nature 452, 1007-1011.

55. Nakagawa, T., and Vosshall, L. B. (2009). Controversy and consensus: noncanonical signaling mechanisms in the insect olfactory system. Current Opinion in Neurobiology 19, 284-292.

56. Boto, T., Gomez-Diaz, C., and Alcorta, E. (2010). Expression analysis of the 3 G-protein subunits, Galpha, Gbeta, and Ggamma, in the olfactory receptor organs of adult Drosophila melanogaster. Chemical Senses 35, 183-193.

57. Jacquin-Joly, E., Francois, M. C., Burnet, M., Lucas, P., Bourrat, F., and Maida, R. (2002). Expression pattern in the antennae of a newly isolated lepidopteran Gq protein alpha subunit cDNA. European Journal of Biochemistry / FEBS 269, 2133-2142.

58. Kain, P., Chakraborty, T. S., Sundaram, S., Siddiqi, O., Rodrigues, V., and Hasan, G. (2008). Reduced odor responses from antennal neurons of G(q)alpha, phospholipase Cbeta, and rdgA mutants in Drosophila support a role for a phospholipid intermediate in insect olfactory transduction. The Journal of Neuroscience : the Official Journal of the Society for Neuroscience 28, 4745-4755.

59. Laue, M., Maida, R., and Redkozubov, A. (1997). G-protein activation, identification and immunolocalization in pheromone-sensitive sensilla trichodea of moths. Cell and Tissue Research 288, 149-158.

60. Miura, N., Atsumi, S., Tabunoki, H., and Sato, R. (2005). Expression and localization of three $\mathrm{G}$ protein alpha subunits, Go, Gq, and Gs, in adult antennae of the silkmoth (Bombyx mori). The Journal of Comparative Neurology 485, 143-152.

61. Talluri, S., Bhatt, A., and Smith, D. P. (1995). Identification of a Drosoph- 
ila G protein alpha subunit (dGq alpha-3) expressed in chemosensory cells and central neurons. Proceedings of the National Academy of Sciences of the United States of America 92, 11475-11479.

62. Perez, C. A., Huang, L., Rong, M., Kozak, J. A., Preuss, A. K., Zhang, H., Max, M., and Margolskee, R. F. (2002). A transient receptor potential channel expressed in taste receptor cells. Nature Neuroscience 5, 11691176.

63. Zhang, Y., Hoon, M. A., Chandrashekar, J., Mueller, K. L., Cook, B., Wu, D., Zuker, C. S., and Ryba, N. J. (2003). Coding of sweet, bitter, and umami tastes: different receptor cells sharing similar signaling pathways. Cell 112, 293-301.

64. Bachmanov, A. A., and Beauchamp, G. K. (2007). Taste receptor genes. Annual Review of Nutrition 27, 389-414.

65. Nelson, G., Chandrashekar, J., Hoon, M. A., Feng, L., Zhao, G., Ryba, N. J., and Zuker, C. S. (2002). An amino-acid taste receptor. Nature 416, 199202.

66. Nelson, G., Hoon, M. A., Chandrashekar, J., Zhang, Y., Ryba, N. J., and Zuker, C. S. (2001). Mammalian sweet taste receptors. Cell 106, 381-390.

67. Meyerhof, W., Batram, C., Kuhn, C., Brockhoff, A., Chudoba, E., Bufe, B., Appendino, G., and Behrens, M. (2010). The molecular receptive ranges of human TAS2R bitter taste receptors. Chemical Senses 35, 157-170.

68. Glendinning, J. I., Davis, A., and Ramaswamy, S. (2002). Contribution of different taste cells and signaling pathways to the discrimination of "bitter" taste stimuli by an insect. The Journal of Neuroscience : the Official Journal of the Society for Neuroscience 22, 7281-7287.

69. Glendinning, J. I., and Hills, T. T. (1997). Electrophysiological evidence for two transduction pathways within a bitter-sensitive taste receptor. Journal of neurophysiology 78, 734-745.

70. Sato, K., Tanaka, K., and Touhara, K. (2011). Sugar-regulated cation channel formed by an insect gustatory receptor. Proceedings of the National Academy of Sciences of the United States of America 108, 1168011685.

71. Ueno, K., Kohatsu, S., Clay, C., Forte, M., Isono, K., and Kidokoro, Y. (2006). Gsalpha is involved in sugar perception in Drosophila melanogaster. The Journal of Neuroscience : the Official Journal of the Society for Neuroscience 26, 6143-6152.

72. Bredendiek, N., Hutte, J., Steingraber, A., Hatt, H., Gisselmann, G., and Neuhaus, E. M. (2011). Go alpha is involved in sugar perception in Drosophila. Chemical Senses 36, 69-81.

73. Ditzen, M., Pellegrino, M., and Vosshall, L. B. (2008). Insect odorant receptors are molecular targets of the insect repellent DEET. Science 319, 1838-1842.

74. Dogan, E. B., Ayres, J. W., and Rossignol, P. A. (1999). Behavioural mode of action of deet: inhibition of lactic acid attraction. Medical and Veterinary Entomology 13, 97-100.

75. Syed, Z., and Leal, W. S. (2008). Mosquitoes smell and avoid the insect repellent DEET. Proceedings of the National Academy of Sciences of the United States of America 105, 13598-13603.

76. Kain, P., Badsha, F., Hussain, S. M., Nair, A., Hasan, G., and Rodrigues, V. (2010). Mutants in phospholipid signaling attenuate the behavioral response of adult Drosophila to trehalose. Chemical Senses 35, 663-673. 